Original Research Article

\title{
Impact of metformin on the severity and outcomes of ischemic stroke
}

\author{
Vahid Abbasi $^{1}$, Firouz Amani ${ }^{2 *}$, Ameneh Faraji-Almoti ${ }^{3}$
}

${ }^{1}$ Department of Neurology, Faculty of Medicine, Ardabil University of Medical Science, Ardabil, Iran

${ }^{2}$ Department of Biostatistics, Faculty of Medicine, Ardabil University of Medical Science, Ardabil, Iran

${ }^{3}$ Faculty of Medicine, Ardabil University of Medical Science, Ardabil, Iran

Received: 27 January 2018

Accepted: 06 March 2018

\section{*Correspondence to:}

Dr. Firouz Amani,

Email: biostat.f@gmail.com

Copyright: (C) the author(s), publisher and licensee Medip Academy. This is an openaccess article distributed under the terms of the Creative Commons Attribution NonCommercial License, which permits unrestricted noncommercial use, distribution, and reproduction in any medium, provided the original work is properly cited.

\begin{abstract}
Background: Stroke is the third most common cause of death in the United States and the most commonly diagnosed neurological disorder. About 750,000 strokes occur annually in the United States and about 150,000 people die as a result of stroke. The aim of this study was evaluation of the effect of Metformin on complication of ischemic strokes.

Methods: In this randomized, double-blind clinical trial study, 100 patients with ischemic stroke will be assigned randomly into two groups A and B. The National Institutes of Health Stroke Scale (NIHSS) will be used to evaluate the clinical manifestations of ischemic stroke. The two groups will be followed up for 3 months. Metformin 500mg twice in a day will be administered for seven days for group (A) and placebo will be administered for seven days for group (B). Blood glucose will be checked every 6 hours and will be recorded on the blood glucose (BS) chart. Before the intervention, the NIHSS questionnaire will be recorded in one day, three days, seven days and one month, two months, and three months after the intervention will be followed up respectively.

Results: In the present study, according to the neuro-protective effects of metformin, there is a significant difference in metformin taking in the reduction of NIHSS Score in non-diabetic stroke patients. There was a significant association in metformin taking and decrease in NIHSS scores in patients with cortical ischemic stroke.

Conclusions: According to the results, in patients with cortical stroke, there weren't a significant difference in NIHSS between the two groups in the first, third and seventh days but in the first, second and third months after intervention the difference was significant. Also, the results showed that metformin reduced the severity and stroke symptoms and accelerated recovery and functional output in patients with cortical stroke after the first, second and third months.
\end{abstract}

Keywords: Complications, Metformin, Recovery, Stroke

\section{INTRODUCTION}

Stroke is a non-communicable disease among the elderly population that is the third leading cause of death in developed countries after coronary artery diseases and cancers. According WHO report, 56.4 million deaths occurred worldwide in 2015 that $54 \%$ of them were among the top ten causes of death. Yearly about 750000 stroke have been occurred in USA and about 150000 of them have been died due to stroke. The incidence of stroke increases with age and about two third of stroke cases occur in upper 65 years old. In Iran the occurrence of stroke 10 year lower than world and several risk factors including age, sex, alcohol, smoking, high cholesterol, OCP, genetic and HTN are involved in the pathogenesis of stroke among people. Stroke is the main cause of physical disability among society's people which ws characterized 
by the onset of acute neurological symptoms for 24 hours. ${ }^{1-4}$

Neurological symptoms are caused by the involvement of the central nervous system as a result of impaired cerebral blood flow which was determined by getting history. The location of the CNS is guessed according to the type of symptoms and diagnosed by neurologic examination and confirmed by uses CT-scan and MRI. 2,3,5,6

The UKPDS study reported that treatment with Metformin decreases the risk of large vascular disease similar to small vascular disease. This is the opposite of other therapies that only reduce the deaths caused by sall vessels. The study showed that metformin protects cells from hypoxia and non-neuronal ischemia.

The protective effects of metformin may be due to AMPK activity. Research results indicated that metformin injection was performed 30 minutes after reperfusion injury in a complete brain ischemia in animal models involving 4 brain vessels and the deaths of the cells advance toward apoptosis..$^{7-9}$

Also cerebrovascular disease is the most common neurological disease which can lead to complications or mortality. The incidence of ischemic stroke increases with age, and almost two thirds of cases occur in people over 65 years. ${ }^{10}$

Considering the protective effects of metformin in preventing secondary damage and due to lack of similar study in this area, the aim of this study was to investigate the impact of Metformin on the Severity and Outcomes of Ischemic Stroke.

\section{METHODS}

\section{Study design and patients}

This clinical trial study has been done on 100 patients with ischemia stroke which randomly assigned to two groups A and B. Inclusion criteria of the study is Ischemic stroke patients and focal neurological symptoms. Exclusion criteria of the study is intracerebral hemorrhage (ICH); Subarachnoid hemorrhage (SAH); subdural hematoma (SDH); hypoglycemia; contraindications for metformin use; diabetic patients; venous sinus thrombosis and drug side effects. The National Institutes of Health Stroke Scale (NIHSS) will be used to evaluate the clinical manifestations of ischemic stroke. Two groups were followed-up for three month and Metformin $500 \mathrm{mg}$ was administrated for patients in group A and placebo for patients in group B twice a day for seven days. If any complications are detected, the patient will be excluded from the study.

Blood glucose in patients each 6 hour was checked and registered in chart of $\mathrm{BS}$ and in case of see any complications, the patient extracted from the study. Before start the intervention, the NIHSS questionnaire was completed in baseline and 1, 3, 7 days and 1,2 and 3 month after intervention completed for follow-up.

\section{NIHSS questionnaire}

The questionnaire NIHSS formed of 11 questions and the total score is in range 0 to 42 and each question had score 0 to 4 . The score 0 for normal performance and the high scores show the upper degree of neourologic disorders in patients. The necessary tests such as level of consciousness (LOC), Eye movements, Field of vision, Fractional paresis, Arm movements (paralysis), Foot movements, Ataxia and sensory impairment, Ability to speak and Dysarthria was performed according to standard criteria of patients.

\section{Statistical methods}

Collected data were analyzed by statistical methods in SPSS version 19.

\section{RESULTS}

There were Fifty sex present of all patients were male and rest of them were female. The mean age of patients in Metformin group (A) was 68.9 \pm 10.6 years (range 42-90) and placebo group (B) was $67 \pm 11.63$ years (range $41-86$ ). The prevalent stroke risk factor was HTN with $43 \%$.

\section{Cortical stroke}

The difference in NIHSS scores between two groups in patients with cortical stroke wasn't significant in days 1 $(\mathrm{p}=0.5), 2(\mathrm{p}=0.66)$ and $7(\mathrm{p}=0.18)$ after treatment by Metformin but the difference was significant in end of first month $(\mathrm{p}=0.038)$, second month $(\mathrm{p}=0.001)$ and third month $(\mathrm{p}=0.001)$ (Figure 1).

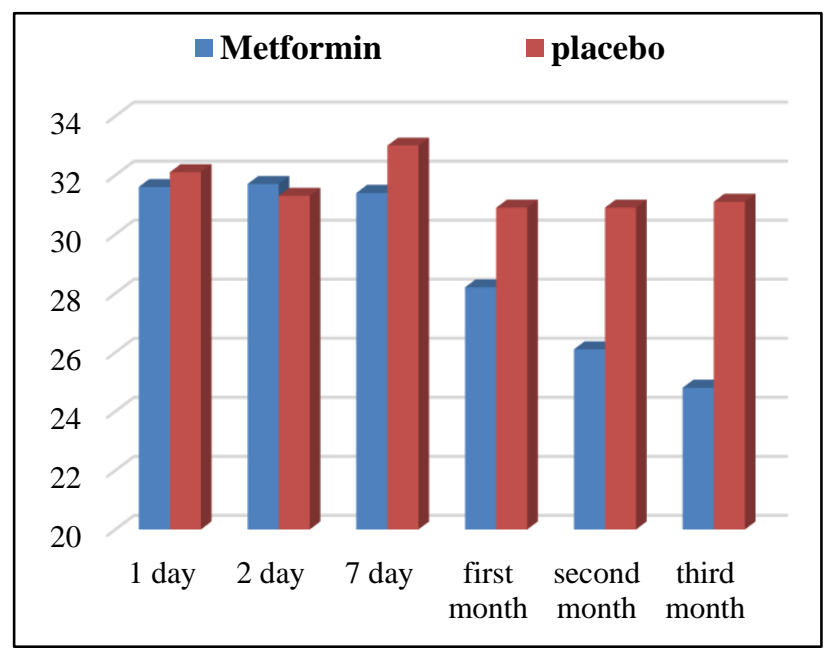

Figure 1: Compare the mean of NIHSS scores between two groups by times after intervention in cortical stroke. 


\section{Brain stem stroke}

The difference in NIHSS scores between two groups in patients with brain stem stroke wasn't significant in days $1(p=0.75), 2(p=0.56)$ and $7(p=0.48)$ after treatment by Metformin and in the end of first month $(\mathrm{p}=0.57)$, second month $(\mathrm{p}=0.51)$ and third month $(\mathrm{p}=0.33)$ (Figure 2$)$.

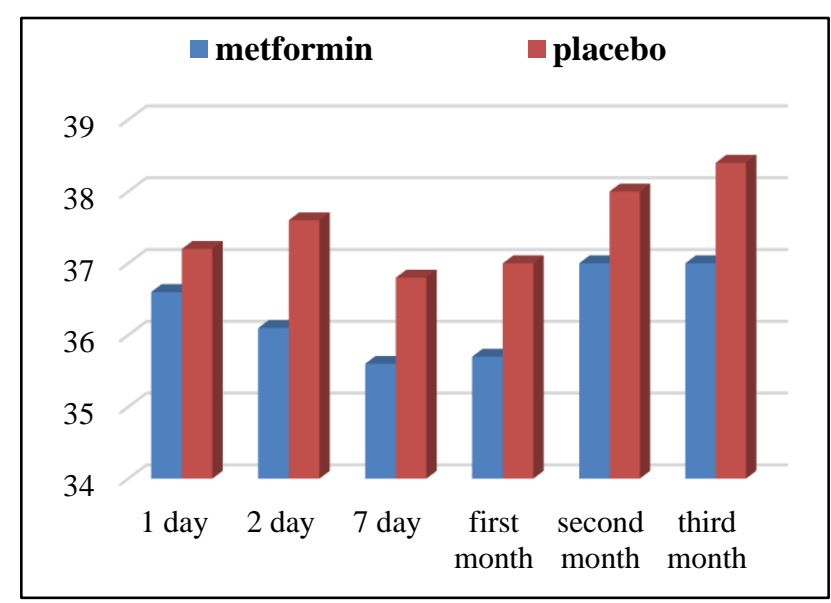

Figure 2: Compare the mean of NIHSS scores between two groups by times after intervention in brain stem stroke.

\section{Lacunar stroke}

The difference in NIHSS scores between two groups in patients with Lacunar stroke wasn't significant in days 1 $(\mathrm{p}=0.69), 2(\mathrm{p}=0.58)$ and $7(\mathrm{p}=0.51)$ after treatment by Metformin and in the end of first month $(p=0.46)$, second month $(\mathrm{p}=0.55)$ and third month $(\mathrm{p}=0.21)$ (Figure 3$)$.

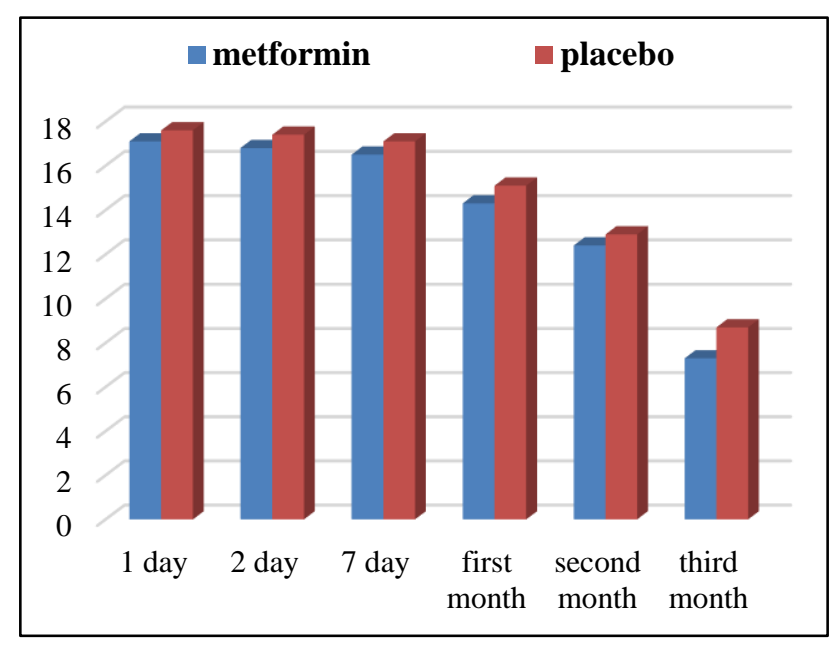

Figure 3: Compare the mean of NIHSS scores between two groups by times after intervention in lacunar stroke.

\section{DISCUSSION}

In line with our study, Mima and et al in a study in 2016, showed that treatment with Metformin in patients with stroke was associated with mild brain symptoms $(\mathrm{p}=0.026)$. But neural function didn't show significant relation. Also patients with history of stroke, gain taking Metformin on improving symptoms $(\mathrm{p}=0.046) .^{5}$

According to the $\mathrm{Wu}$ and et al study in 2016 which has been done on ICH diabetic patients, results showed that Metformin was related with death below 90 days $(p=0.014)$ which was in line with our study results. ${ }^{11}$

Venna and et al in study 2014, showed that there was inconsistent evidence on effect of metformin on RSN as a marker for mortality in repeated $\mathrm{CV}$ and Atrothrombotic ischemia stroke. $^{12}$

According to the study of Kuwashiro and et al in 2012, using metformin in patients with stroke to prevent, had about $9 \%$ positive and $6 \%$ negative results that there wasn't significant relation between taking metformin and occurrence stroke. The severity of stroke defined by NIHSS and the mild neurologic defined as a score low than 3 for NIHSS. According to the function results, postoperative dysfunction after discharge assesed by MRS and the desirable performance defined as MRS score 2 or below. ${ }^{7,13}$

There was significant difference between patients which used metformin before stroke and in diabetic patints that not had proper treatment. On the other hand, given the effects of the previous use of anti-diabetic drugs, currently there was no evidence indicating the improvement in the severity or outcome of stroke. ${ }^{8,9,12-15}$

In contrast, use metformin was considered as a proper factor in reducing the severity of stroke in the study population of Mima and et al, study that in non-diabetic patients with stroke ( $64 \%$ of all patients), about $75 \%$ had NIHSS below 3 and the effects of metformin was observed on functional outcomes only in the mild to severe stroke. In addition to the initial score of NIHSS, occurrence of stroke relapse was related with increasing stroke severity and mild prognosis of stroke..$^{5,16,17}$

Jiang and et al in a study showed that the drugs such as metformin, pioglitazone and semaglutin were effective in the decreasing the risk of stroke. ${ }^{18}$

In a sample of 14856 diabetic patients from Taiwan after 4 years follow-up, the relation between metformin uses and stroke reducing wasn't significant. A multi-center study conducted in 1998 by UKPDS, presented evidence that treatment with metformin in comparison with insolin and SU deal to reducing the coronery side effects related to the T2D that's it deals to accelerate the use of metformin in diabetic treatment. ${ }^{13,19}$

In this study in line with other studies, results showed that taking metformin in non-diabetic patients with stroke could cause to decreasing the stroke intensity and its 
effects such as functional effects which was assessed in this study by NIHSS.

\section{CONCLUSION}

In cortical stroke, the difference in NIHSS between two groups wasn't significant in first, third and seventh day after intervention but it was significant in one, two and three months after intervention. The results of this study showed that taking metformin was reduced the intensity and symptoms of stroke and also deal to accelerated recovery and functional output in patients with cortical stroke one, two and three months after intervention.

Funding: No funding sources Conflict of interest: None declared

Ethical approval: The study was approved by the Institutional Ethics Committee of Ardabil University and registered by code IR-ARUMS-REC-2016-76

\section{REFERENCES}

1. Simon R, Greenberg D, Aminoff M. Clinical neurology $9^{\text {th }}$ Edition; 2015.

2. Trevor AJ, Katzung BG, Masters SB, Kruidering-Hall M. Basic and Clinical Pharmacology $13^{\text {th }}$ Edition: McGraw-Hill Medical New York; 2015.

3. Arbeláez-Quintero I, Palacios M. To Use or Not to Use Metformin in Cerebral Ischemia: A Review of the Application of Metformin in Stroke Rodents. Stroke Research and Treatment. 2017;1-13.

4. Abbasi V, Amani F, Aslanian R, Hoseinkhani A, Zakeri A. Epidemiological Study of Stroke in Ardabil, Iran: a Hospital Based-Study. J Neurol Disord Stroke. 2017;5(3):1128.

5. Mima Y, Kuwashiro T, Yasaka M, Tsurusaki Y, Nakamura A, Wakugawa $Y$, et al. Impact of Metformin on the Severity and Outcomes of Acute Ischemic Stroke in Patients with Type 2 Diabetes Mellitus. J Stroke Cerebrovasc Dis [Internet]. 2016;25(2):436-46. Available at: http://www.sciencedirect.com/science/article/pii/ S1052305715005686

6. Dadwal P, Mahmud N, Sinai L, Azimi A, Fatt M, Wondisford FE, et al. Activating endogenous neural precursor cells using metformin leads to neural repair and functional recovery in a model of childhood brain injury. Stem cell reports. 2015;5(2):166-73.

7. Ashabi G, Khalaj L, Khodagholi F, Goudarzvand M, Sarkaki A. Pre-treatment with metformin activates Nrf2 antioxidant pathways and inhibits inflammatory responses through induction of AMPK after transient global cerebral ischemia. Metab Brain Dis. 2015;30(3):747-54.

8. Abd-Elsameea A, Moustaf A, Mohamed A. Modulation of the oxidative stress by metformin in the cerebrum of rats exposed to global cerebral ischemia and ischemia/reperfusion. Eur Rev Med Pharmacol Sci. 2014;18(16):2387-92.
9. Deng T, Zheng YR, Hou WW, Yuan Y, Shen Z, Wu XL. Pre-stroke Metformin Treatment is Neuroprotective Involving AMPK Reduction. Neurochem Res. 2016;41(10):2719-27.

10. Abbasi V, Fattahzadeh-Ardalani G, Safarnejad P, Aslanian R. Albumin impact on clinical practice and complications of ischemic stroke in patients with stroke. Int J Basic Clin Pharmacol. 2016;5:2114-7.

11. Wu TY, Campbell BC, Strbian D, Yassi N, Putaala J, Tatlisumak $\mathrm{T}$, et al. Impact of pre-stroke sulphonylurea and metformin use on mortality of intracerebral haemorrhage. European Stroke Journal. 2016;1(4):302-9.

12. Venna VR, Li J, Hammond MD, Mancini NS, Mccullough LD. Chronic metformin treatment improves post-stroke angiogenesis and recovery after experimental stroke. Eur J Neurosci. 2014;39(12):2129-38.

13. Kuwashiro T, Kamouchi M, Ago T, Hata J, Sugimori $\mathrm{H}$, Kitazono $\mathrm{T}$, et al. The factors associated with a functional outcome after ischemic stroke in diabetic patients: the Fukuoka Stroke Registry. Journal of the neurological sciences. 2012;313(1):110-4.

14. Zhou C, Sun R, Zhuang S, Sun C, Jiang Y, Cui Y, et al. Metformin prevents cerebellar granule neurons against glutamate-induced neurotoxicity. Brain Res Bull. 2016;121:241-5.

15. Jia J, Cheng J, Ni J, Zhen X. Neuropharmacological Actions of Metformin in Stroke. Curr Neuropharmacol. 2015;13(3):389-94.

16. Liu Y, Tang G, Li Y, Wang Y, Chen X, Gu X, et al. Metformin attenuates blood-brain barrier disruption in mice following middle cerebral artery occlusion. Journal of neuroinflammation. 2014;11(1):1.

17. Jin Q, Cheng J, Liu Y, Wu J, Wang X, Wei S, et al. Improvement of functional recovery by chronic metformin treatment is associated with enhanced alternative activation of microglia/macrophages and increased angiogenesis and neurogenesis following experimental stroke. Brain, behavior, and immunity. 2014;40:131-42.

18. Jiang T, Yu JT, Zhu XC, Wang HF, Tan MS, Cao L, et al. Acute metformin preconditioning confers neuroprotection against focal cerebral ischaemia by pre-activation of AMPK-dependent autophagy. British Journal of Pharmacology. 2014;171:3146-57.

19. Cheng YY, Leu HB, Chen TJ, Chen CL, Kuo CH, Lee $\mathrm{SD}$, et al. Metformin-inclusive therapy reduces the risk of stroke in patients with diabetes: a 4-year follow-up study. Journal of Stroke and Cerebrovascular Diseases. 2014;23(2):e99-e105.

Cite this article as: Abbasi V, Amani F, Ameneh FA. Impact of metformin on the severity and outcomes of ischemic stroke. Int J Basic Clin Pharmacol 2018;7:744-7. 